\title{
White associated to Grayish-Blue: Vitiligo developed near nevus of Ota on the face of a teenager female
}

\section{Sara Dahhouki, Kaoutar Achehboune, Khadija Issoual, Sara Elloudi, Hanane Baybay, Fatima Zahra Mernissi}

Department of Dermatology, Hassan II Hospital University, Fez, Morocco

Corresponding author: Dr. Sara Dahhouki, E-mail: dahhoukisara@gmail.com

Nevus of Ota is a type of dermal melanocytosis, it is distributed along the ophthalmic and maxillary divisions of the trigeminal nerve and presents as a blue or gray patch on the face [1]. In the opposite, vitiligo is a benign disorder,secondary to chronic degradation of melanocytes in epidermis and follicles, characterized by depigmented lesions [2]. Nevus of Ota is a rare disorder, and the appearance of vitiligo lesions withassociated to nevus of Ota is exceptional. Herein, we report a new case of a teenager with this association [3].

A 16-year-old female presented in our clinical with hypochromic lesions on the face4 monthsearlier. A history of bluish patches which had been present since birth was reported. Physical examination showed white macula on the posterior part of cheek, poorly bounded with irregular contours, with better evidence under Wood's lamp (Figs. la and lb). We described as well a blue-grayish macula on the dermatome of maxillary divisions of the trigeminal nerve, adjacent to the previous lesion, which dermoscopy revealed blue-grayish structures with iridescent reflections (Figs. 2a and 2b).

\section{Consent}

The examination of the patient was conducted according to the Declaration of Helsinki principles.

The authors certify that they have obtained all appropriate patient consent forms. In the form the patient(s) has/have given his/her/their consent for his/her/their images and other clinical information to be reported in the journal. The patients understand that their names and initials will not be published and due efforts

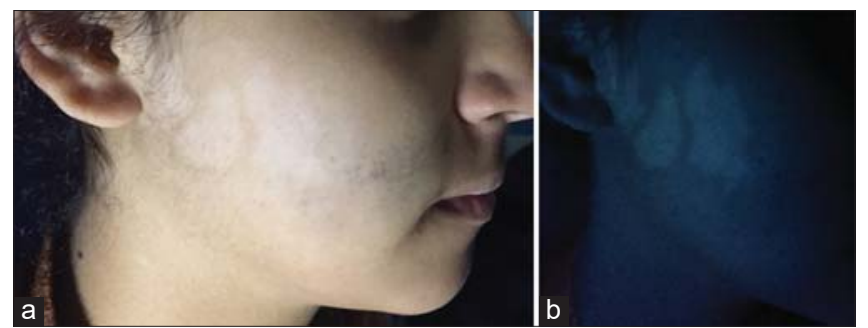

Figure 1: ( $a$ and $b)$ Hypochromic macula on the posterior part of cheek, poorly bounded with irregular contours, with better evidence under Wood's lamp.

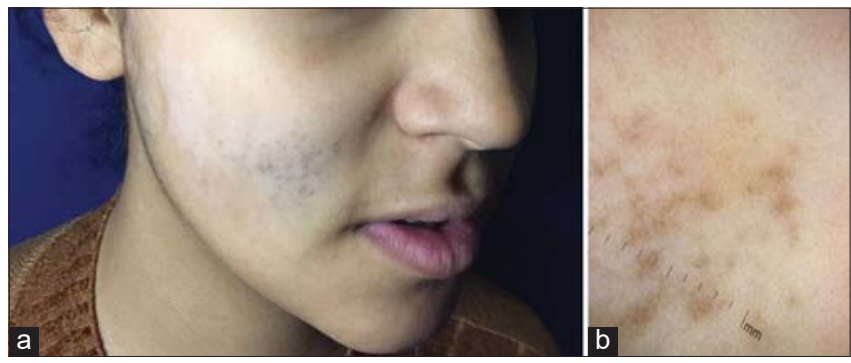

Figure 2: $(a$ and $b)$ A blue-grayish macula on the dermatome of maxillary divisions of the trigeminal nerve, adjacent to the previous lesion, which dermoscopy revealed blue-grayish structures with iridescent reflections.

will be made to conceal their identity, but anonymity cannot be guaranteed.

\section{REFERENCES}

1. Ahogo K-C, Gbery I-P, Vagamon B, Ouattara O-A, Kouassi K-A, Kourouma H-S, et al. Vitiligo dévéloppé sur une mélanocytose dermique (nævus de Ota) chez une patiente à peau foncée. Ann Dermatol Vénéréol. 2017;144:712-4.

2. Ahn J-J, Lee J-H, Shin M-K, Lee M-H. Two cases of vitiligo

\footnotetext{
How to cite this article: Dahhouki S, Achehboune K, IssoualK, Elloudi S, Baybay H, Mernissi FZ. White associated to Grayish-Blue: Vitiligo developed near nevus of Ota on the face of a teenager female. Our Dermatol Online. 2020;11(e):e99.1-e99.2.

Submission: 03.06.2020; Acceptance: 02.08.2020

DOI: $10.7241 /$ ourd.2020e.99
} 
www.odermatol.com

developed on the persisting dermal melanocytosis: is there a difference between epidermal melanocytes and dermal melanocytes? Ann Dermatol. 2013;25:226-8.

3. El Kadiri S, Bay Bay H, Chaoui R, Douhi Z, Elloudi S, Mernissi FZ. A new dermoscopic fi nding in Ota nevus. Our Dermatol Online. 2020;11:e11.1-e11.2.
Copyright by Sara Dahhouki, et al. This is an open access article distributed under the terms of the Creative Commons Attribution License, which permits unrestricted use, distribution, and reproduction in any medium, provided the original author and source are credited.

Source of Support: Nil, Conflict of Interest: None declared. 